Proceedings of the 10th International Ruminant Reproduction Symposium (IRRS 2018); Foz do Iguaçu, PR, Brazil, September 16th to 20th, 2018.

\title{
Pathogenesis of uterine diseases in dairy cattle and implications for fertility
}

\author{
Marc Drillich*, Karen Wagener \\ University Clinic for Ruminants, Clinical Unit for Herd Health Management in Ruminants, Department for Farm Animals and \\ Veterinary Public Health, University of Veterinary Medicine (Vetmeduni), Vienna, Austria.
}

\begin{abstract}
Uterine diseases in cattle occur at all stages of the reproduction cycle but the majority of cases is found in the postpartum period. The inflammation of the uterus is generally defined as metritis or endometritis, with several graduations, e.g. puerperal metritis, clinical metritis, clinical or subclinical endometritis. Whether uterine diseases have a negligible, moderate or detrimental effect on fertility is still under discussion and depends on definitions and classification. In the past, it was assumed that the pregnant uterus is free of pathogens, but recent studies found several species including pathogens in the uterus and endometrium of pregnant cows. After parturition, a broad diversity of bacteria with $>200$ different species has been found in the early postpartum period. Not all of these bacteria, however, are considered as pathogens. Furthermore, bacteriological findings provide only evidence for infection but not for inflammation. For some bacteria, particularly Escherichia coli and Trueperella pyogenes pathogenic mechanism resulting in metritis and endometritis have been elucidated in detail. The role of bacteria that can be regarded as opportunistic or potential pathogens, e.g. Bacillus pumilus, is still under investigation. The understanding of the uterine microbiota and its interactions is increasing with the use of modern high-resolution techniques such as Fouriertransform infrared spectroscopy. Endometrial cytology provides additional information about alterations in the endometrium. Knowledge of innate uterine defense mechanism in cattle has increased a lot in the recent past. It can be speculated that improving or modulating uterine defense mechanism will be part of future prevention and treatment approaches beyond the use of antimicrobials. In this context, cellular and molecular defense mechanisms have been in the focus of interest, e.g. the role of interleukins or mucins. This review gives a short overview on some aspects of recent research on uterine diseases in cattle.
\end{abstract}

Keywords: endometritis, metritis, microbiota, uterine defense mechanism, uterine disease.

\section{Introduction}

Reproductive performance of cows and heifers is one of the key parameters reflecting the economic success of dairy farming. Several fertility parameters can be used to describe negative effects of uterine diseases on reproductive performance, e.g. days to first service, estrus detection rate, and probability of pregnancy per insemination. Days to first service and estrus detection rate are mainly affected by management (time for estrus detection, accuracy of estrus detection, claw trimming, and several other aspects related to management) and to lesser extent by cows' diseases, e.g. cysts, conception risk is strongly related to uterine health. Thus, the prevention of uterine diseases, sufficient detection of affected cows and efficacious treatment strategies are important aspects of the fertility management of dairy cows.

Inflammation of the uterus, defined as metritis or endometritis is one of the most common disorders in the postpartum period of dairy cattle. Puerperal metritis is characterized by abnormal discharge, enlarged uterus, dullness, and a rectal temperature $>39.5 \mathrm{C}$ (Sheldon et al., 2006). Puerperal metritis is also referred to as acute metritis, toxic puerperal metritis or septic metritis and occurs usually within the first 10 days after parturition.

Clinical or chronic endometritis is defined by the occurrence of purulent or mucopurulent vulvar discharge detected more than 3 weeks postpartum. In contrast to acute metritis, chronic endometritis is not associated with elevated temperature and the animals do not show general signs of illness or a depressed attitude. It has been suggested to perform a clinical examination for endometritis later than 21 or 26 days postpartum. An earlier examination results in a greater proportion of false-positive diagnoses (LeBlanc et al., 2002). Although the term endometritis is well established for cows with vaginal discharge, there is clear evidence that the origin of pus in the vagina is not always the endometrium but could also be the cervix or vagina. Furthermore, Dubuc et al. (2010) found a poor agreement between cytological endometritis diagnosed by uterine cytology and vaginal discharge. Thus, Dubuc et al. (2010) suggested the term purulent vaginal discharge (PVD) as a more accurate description than clinical endometritis. The authors of this paper, however, prefer to follow the classical rules of medical terminology for a disease and not to use symptoms as synonymous for a diagnosis.

For the definition and diagnosis of subclinical or cytological endometritis, cytological samples are taken from the endometrium to determine the percentage of polymorphonuclear cells (PMN) in the smears (Kasimanickam et al., 2004). A proportion of $5 \%$ PMN can be regarded as diagnostic for subclinical endometritis (Madoz et al., 2013). Research on subclinical endometritis and diagnostic techniques has been recently reviewed by De Boer et al. (2014) and Wagener et al. (2017a). 


\section{Uterine infection, uterine microbiota}

The contamination of the uterus after parturition with a broad diversity of bacteria is regarded as inevitable. This process with contamination, elimination and subsequent re-contamination is complex and not fully understood (Földi et al., 2006; Wagener et al., 2015). This concept becomes even more complex with the fact that the pregnant uterus is not sterile, as thought for many years, but may be colonized with several bacterial species including pathogens such as Trueperella pyogenes (Karstrup et al. 2017; Moore et al. 2017). These findings open a new discussion about long-lasting effects of uterine infections but also on pathogenic mechanism of bacteria, i.e. under which conditions an infection has detrimental effects - or not on conception and pregnancy. Furthermore, there is some evidence that bacteria may also invade the uterus via blood, e.g from the gut (Jeon et al., 2017). Whether natural defense mechanisms eliminate the majority of invaded bacteria or clinical diseases manifest depends on the bacterial load and pathogenicity of bacteria as well as on the immune status of the cow (Sheldon et al., 2002; LeBlanc et al., 2011; Jeon et al., 2016). Thus, the occurrence of metritis and endometritis is not only a question of the invading bacterial species. Understanding these interactions and the changes in bacterial composition of the uterine microbiota prior to the appearance of clinical signs of a disease may play a crucial role for the development of optimal prevention and intervention strategies in the future (Madoz et al., 2014).

Persistent bacterial infection of the uterus may cause metritis and endometritis. Escherichia coli, $T$. pyogenes, Fusobacterium necrophorum and Prevotalla spp. are common intrauterine pathogens (Földi et al., 2006; Sheldon et al., 2006), although the bacterial virulence factors involved in uterine pathology and the exact mechanism of bacterial pathogenicity are largely unknown (Bicalho et al., 2012). In the recent past, however, the effects of uterine infections with $E$. coli and $E$. coli-derived endotoxins lipopolysaccharides (LPS) have been studied and described in detail (Williams et al., 2008; Sheldon et al., 2009, 2010; Herath et al., 2009; Goldstone et al., 2014). It has been shown that LPS, a component of the bacterial membrane, has detrimental effects on the endometrium, disrupts uterine and also ovarian function, but also plays role in the innate immune response. One mechanism is that Toll-like receptors (TLR) on the endometrial cells bind LPS, leading to secretion of cytokines and chemokines. Chemokines attract neutrophils and macrophages to eliminate bacteria. There is evidence that a specific strain of E. coli, EnPEC, is the main pathogen for metritis (Sheldon et al., 2009).

Whereas E. coli can be regarded as one of the major pathogens associated with early postpartum metritis, T. pyogenes is supposed to be responsible for endometritis later in the puerperium. In the past, preceding infections with $E$. coli were assumed to facilitate subsequent persistence of $T$. pyogenes infections (Dohmen et al., 1995, 2000). Recent studies, however, did not support this hypothesis (Prunner et al., 2014; Wagener et al., 2014b). In contrast, a positive correlation between occurrence of Streptococcus uberis on day 3 postpartum and subsequent $T$. pyogenes infections was found, which is in line with previous studies reporting an increased risk of purulent vaginal discharge related to the presence of $\alpha$-hemolytic Streptococci (Werner et al., 2012). Furthermore, it was shown that specific subtypes of $S$. uberis were associated with the uterine health status of postpartum dairy cows (Wagener et al., 2014b).

A study from Amos et al. (2014) provided evidence that the exotoxin pyolysin (PLO) is the major virulence factor of $T$. pyogenes. Interestingly, endometrial stroma cells were more sensitive to PLO mediated cytolysis than epithelial cells. Thus, it seems that detrimental effects of $T$. pyogenes at the endometrium occur once the epithelium layer is disrupted after parturition. However, the PLO gene is present in all $T$. pyogenes strains and recombinant PLO alone did not stimulate a host inflammation response. Thus, further research should elucidate if the cellular response, that is commonly associated with bacterial infections, is triggered by other virulence factors of $T$. pyogenes (Bicalho et al., 2012) or by co-occurring other intrauterine bacterial species.

Beside E.coli and T. pyogenes, a broad variety of other bacterial species can be found in the bovine postpartum uterus (Földi et al., 2006; Prunner at al., 2014; Wagener et al., 2015). Particularly, the application of high-resolution techniques brought deep insights into the uterine microbiota. Metagenomic studies (Santos et al., 2011; Santos and Bicalho, 2012) and analyses performed with the aid of chemometricassisted Fourier-transform infrared (FTIR) spectroscopy (Prunner et al., 2014; Wagener et al., 2015) indicated that the bovine uterine microbial community is diverse, highly dynamic and even much more complex than previously thought. In one of our studies, we could show that the aerobic uterine microflora comprised a huge diversity of bacteria belonging to 202 different species, representing 76 genera (Wagener et al., 2015). Members of the genus Bacillus, Streptococcus, Enterococcus and coagulase negative staphylococci (CNS) were the most frequently isolated intrauterine bacteria, and have been discussed as potential pathogens or opportunistic contaminants earlier (Westermann et al., 2010; Werner et al., 2012). On species level, the uterine microflora was dominated by $T$. pyogenes, $E$. coli, Staphylococcus xylosus, B. pumilus and S. uberis. It is interesting to see that the microbiota did not change only over time but showed also differences between cows with different uterine health status (Wagener et al., 2015). Additionally, known pathogens, e.g. $T$. pyogenes were identified not only in cows with endometritis but also in clinically healthy cows. Further attention should focus on identifying and characterizing opportunistic pathogens that may synergistically interact with $T$. pyogenes. Detailed information on potential interactions and the interpretation of these findings needs some more investigation.

To gain a deeper insight into mechanism of 
intrauterine infections it is essential to elucidate the role of bacteria that may act as a mediator of inflammatory host response. Recent studies indicate that $S$. uberis and B. pumilus (Wagener et al., 2014b, 2015) might represent such bacterial candidates with a hitherto unknown role in uterine pathology. Both bacteria are prevalent in postpartum dairy cows. $S$. uberis is known as an emerging pathogen for mastitis, but has not been described as uterine pathogen. The rarely described $B$. pumilus was found to be associated with endometritis, but it is still unclear if this species is a causing agent for endometritis or is only an opportunistic contaminant in the inflamed endometrium. Results from in vitro cell culture studies pointed towards a pro-inflammatory potential of $B$. pumilus on endometrial cells (Gärtner et al., 2016).

As shown in some of the above mentioned studies (Santos et al., 2011; Santos and Bicalho, 2012; Wagener et al., 2015), it has to be underlined that in several cows with clinical signs of metritis and endometritis, neither E.coli nor $T$. pyogenes can be detected. In this context, the role of anaerobic bacteria, e.g. Porphorymonas spp., as a causing factor as well as a factor for cure rates after antibiotic treatment of metritis needs to be elucidated more in detail (Jeon et al., 2017, 2018). Additionally, further research is required to understand the association between uterine diseases and hitherto unknown species (Santos et al., 2011; Wagener et al., 2014a).

\section{Molecular mechanism associated with subfertility}

Uterine infections as well as cytological endometritis, which are not necessarily congruent, play a crucial role in subfertility in cows. It seems likely that underlying mechanisms for subfertility can be found on molecular level, as reviewed in detail by Sheldon et al. (2014).

Several studies found differences in endometrial gene expression of pro-inflammatory mediators, such as cytokines, antimicrobial peptides, acute phase proteins (APP) and prostaglandins between healthy cows and subfertile cows with e.g. subclinical or clinical endometritis (Fischer et al., 2010; Drillich et al., 2012; Hoelker et al., 2012; Peter et al., 2015; Ibrahim et al., 2016). Upregulated chemokine mRNA expression is required to mediate and direct the PMN influx into the uterine lumen (Zerbe et al., 2003). This chemoattractive effect has been found e.g. for Interleukin (IL) 8 and CXCL5 (Fischer et al., 2010; Galvão et al., 2011). Cytokines IL1A, IL1B, IL6 and TNF $\alpha$ can be regarded as mediators of nonspecific inflammatory processes but are also physiologically upregulated during the early puerperal period (Gabler et al., 2010). Highest cytokine and acute phase proteins mRNA expression was observed during the third week postpartum regardless of their health status (Gabler et al., 2010; Chapwanya et al., 2012). This supports the hypothesis that a certain immune response is essential for postpartum clearance of the uterus. Thus, it would be helpful for research as well as in practice to use pro-inflammatory markers as a diagnostic tool for uterine inflammation.
Other inflammatory mediators associated with uterine diseases are prostaglandins (PG; Arosh et al., 2002). In cows with subclinical endometritis 21 to 28 days postpartum concentrations of PGF $2 \alpha$ were significantly lower whereas concentrations of PGE2 were higher compared with healthy cow (Baranski et al., 2013). It can be hypothesized that this may relate to a switch from PGF2 $\alpha$ to PGE2 induced by E.coliderived LPS (Herath et al., 2009). Additionally, dysregulated expression of enzymes for PG synthesis (PGES) was found in cows with uterine disorders and reduced fertility (Gabler et al., 2009, 2010; Peter et al., 2015), e.g. endometrial PGE2 synthase cPGES, which catalyzes the conversion from $\mathrm{PGH} 2$ into PGE2, was lower and PGD2 synthase was higher compared with healthy cows. Dys-regulation of PGE synthases might contribute to lower conception rates (Gabler et al., 2010). Detailed research is needed to elucidate long term effects of uterine inflammation in the early postpartum period on fertility that manifests later in lactation. In that context, Peter et al. (2015) provided some evidence that endometrial inflammation has such a long term effect on PGD2 synthase PTGDS. In this study, endometrial mRNA expression of several proinflammatory factors was measured in weekly intervals between 24 and 44 days postpartum. Cows initially diagnosed with subclinical endometritis showed a 3-fold increase in PTGDS expression at the end of the observation period compared with healthy cows. Low levels of $\mathrm{PGD}_{2}$ are required for the maintenance of pregnancy (Saito et al., 2002). This, however, is only one example of several factors involved in fertility that need further investigation. Furthermore, the difference between the changes in gene expression and the occurrence of clinical signs of disease and future fertility should be elucidated.

In a recent study, we observed differences in gene expression of endometrial epithelial cells between subfertile (repeat breeder) cows and healthy heifers (Wagener et al., 2017b). Interestingly, the most pronounced differences were observed for mucins, molecules that are an integral component of the local uterine immune defense. Mucins are anti-adhesive glycoproteins covering epithelial surfaces to protect from bacterial infection and proteolytic attacks. In the uterus, high mucin levels may be desirable after parturition to prevent the establishment of bacterial infections (Sheldon, 2015). In contrary, before embryo implantation, mucin down-regulation of endometrial epithelial cells is required for blastocyst attachment in many species (Braga and Gendler, 1993; Johnson et al., 2001). The results of our previous study support the assumption that dys-regulated MUC4 and MUC12 mRNA expression in the uterus may contribute to subfertility in cows (Wagener et al., 2017b). Also Kasimanickam et al. (2014) suggested a potential relevance of endometrial MUC in subfertile cows.

The effects of an inflamed endometrium on embryo's quality and survival have been show in several studies (Hill and Gilbert, 2008; Drillich et al., 2012; Hoelker et al., 2012). From a study with superovulated cows and flushed embryos, we suggested 
that a certain inflammatory endometrial reaction in terms of PMN influx is beneficial for the number of flushed embryos and, thus, for embryo survival (Drillich et al., 2012). Furthermore, changes in endometrial gene expression patterns in cows with and without (subclinical) endometritis included genes involved in cell adhesion and immune modulation (Hoelker et al., 2012). There is evidence for an effect of endometrial PMN infiltration on the early stage embryos. In the first week after fertilisation, altered embryonic gene expression profiles between healthy and subclinical endometritic cows were related to membrane stability, the cell cycle and apoptosis (Hoelker et al., 2012). Underlying mechanisms for dysregulated gene expression in cows with uterine diseases might be elucidated by expression analyses of microRNAs (miRNAs), regulators of post-transcriptional gene expression. Hailemariam et al. (2014) found miRNAs that were differentially expressed in cows with subclinical endometritis, and that are involved in inflammatory responses, cellular proliferation, cell movement, the cell cycle and apoptosis.

\section{Link between negative energy balance and subfertility}

Beside bacterial and viral infections (reviewed by Chastant-Maillard, 2015), several risk factors for endometritis are known, for example calving assistance (Prunner et al., 2014), negative energy balance pre- and post-partum (Potter et al., 2010), hypocalcaemia, and others (Dubuc et al., 2010; Giuliodori et al., 2013).

The in vivo situation of the reproductive tract environment in ruminants is not only influenced by physiological processes of regeneration, inflammation and infection but is also highly dependent on the metabolic situation of the cow (LeBlanc, 2012).

Because of tremendous needs for energy for milk production and decreasing dry matter intake around calving almost all dairy cows undergo a period of negative energy balance (NEB) in the first 100 days of lactation (LeBlanc, 2010). Cows compensate NEB by lipid mobilization, resulting in increased circulating levels of non-esterified fatty acids (NEFA) and betahydroxybutyrate (BHB) and reduced levels of insulin and insulin-like-growth-factor 1 (IGF-1). It is well known that metabolic imbalances during the transition period impair fertility (LeBlanc, 2012). Previous studies have investigated effects of NEB on ovarian function, oocyte and embryo quality (Leroy et al., 2008) and uterine health (Chapinal et al., 2011). A previous study observed altered gene expression of $I G F$ binding protein in the oviduct of cows with NEB; however, the influence of gene expression changes on embryo development were not analyzed (Fenwick et al., 2008). It seems that feed restriction during the dry and postpartum period in general influences global gene expression in the oviduct (Valour et al., 2013). Thus it is important to consider the metabolic situation of the cow in studies investigating underlying reasons for subfertility. Furthermore, the role of the oviduct in cows with uterine diseases needs further evaluation.

\section{Summary}

In the past decades, our knowledge on uterine infections has increased enormously. Particularly the role and mechanisms of pathogenicity of bacteria have been elucidated, as reviewed by Sheldon et al. (2014). Current challenges are the understanding and interpretation of bacterial interactions in the uterine microbiota. Uterine infections cause a cascade of immune reactions in the endometrium which is at least in some ways different from healthy cows that also undergo cellular and molecular changes in the postpartum period. A detailed understanding of these pathogenic mechanisms leading to subfertility might be a key for future prevention and treatment options. Whereas uterine infection and inflammation has been the topic of many studies that elucidated several relations, deeper insights regarding the relationship between uterine diseases and alterations in the oviduct and its functionality is needed to get a broader picture of subfertility in cattle.

\section{References}

Amos MR, Healey GD, Goldstone RJ, Mahan SM, Duvel A, Schuberth HJ, Sandra O, Zieger P, DieuzyLabaye I, Smith DG, Sheldon IM. 2014. Differential endometrial cell sensitivity to a cholesterol-dependent cytolysin links Trueperella pyogenes to uterine disease in cattle. Biol Reprod, 90:1-13.

Arosh JA, Parent J, Chapdelaine P, Sirois J, Fortier MA. 2002. Expression of cyclooxygenases 1 and 2 and prostaglandin E synthase in bovine endometrial tissue during the estrous cycle. Biol Reprod, 67:161-169.

Baranski W, Lukasik K, Skarzynski D, Sztachanska M, Zdunczyk S, Janowski T. 2013. Secretion of prostaglandins and leukotrienes by endometrial cells in cows with subclinical and clinical endometritis. Theriogenology, 80:766-772.

Bicalho ML, Machado VS, Oikonomou G, Gilbert RO, Bicalho RC. 2012. Association between virulence factors of Escherichia coli, Fusobacterium necrophorum, and Arcanobacterium pyogenes and uterine diseases of dairy cows. Vet Microbiol, 157:125-231.

Braga VMM, Gendler SJ. 1993. Modulation of Muc-1 mucin expression in the mouse uterus during the estrus cycle, early pregnancy and placentation. J Cell Sci, 105:397-405.

Chapinal N, Carson M, Duffield TF, Capel M, Godden S, Overton M, Santos JEP, LeBlanc SJ. 2011. The association of serum metabolites with clinical disease during the transition period. $J$ Dairy $S c i$, 94:4897-4903

Chapwanya A, Meade KG, Foley C, Narciandi F, Evans ACO, Doherty ML, Callanan JJ, O'Farrelly C. 2012. The postpartum endometrial inflammatory response: a normal physiological event with potential implications for bovine fertility. Reprod Fertil Dev, 24:1028-1039.

Chastant-Maillard S. 2015. Impact of bovine herpesvirus 4 (BoHV-4) on reproduction. Transbound Emerg Dis, 62:245-251. 
De Boer MW, LeBlanc SJ, Dubuc J, Meier S, Heuwieser W, Arlt S, Gilbert RO, McDougall S. 2014. Invited review: systematic review of diagnostic tests for reproductive-tract infection and inflammation in dairy cows. J Dairy Sci, 97:3983-3999.

Dohmen MJW, Lohuis JACM, Huszenicza G, Nagy P, Gacs M. 1995. The relationship between bacteriological and clinical findings in cows with subacute/chronic endometritis. Theriogenology, 43:1379-1388.

Dohmen MJW, Joop K, Sturk A, Bols PEJ, Lohuis JACM. 2000. Relationship between intra-uterine bacterial contamination, endotoxin levels and the development of endometritis in postpartum cows with dystocia or retained placenta. Theriogenology, 54:10191032.

Drillich M, Tesfaye D, Rings F, Schellander K, Heuwieser W, Hoelker M. 2012. Effects of polymorphonuclear neutrophile infiltration into the endometrial environment on embryonic development in superovulated cows. Theriogenology, 77:570-578.

Dubuc J, Duffield TF, Leslie KE, Walton JS, LeBlanc SJ. 2010. Definitions and diagnosis of postpartum endometritis in dairy cows. J Dairy Sci, 93:5225-5233.

Fenwick MA, Llewellyn S, Fitzpatrick R, Kenny DA, Murphy JJ, Patton J, Wathes DC. 2008. Negative energy balance in dairy cows in associated with specific changes in IGF-binding protein expression in the oviduct. Reproduction, 135:63-75.

Fischer C, Drillich M, Odau S, Heuwieser W, Einspanier R, Gabler C. 2010. Selected proinflammatory factor transcripts in bovine endometrial epithelial cells are regulated during the oestrous cycle and elevated in case of subclinical or clinical endometritis. Reprod Fertil Dev, 22:818-829.

Földi J, Kulcsar M, Pecsi A, Huyghe B, de Sa C, Lohuis JA, Cox P, Huszenicza G. 2006. Bacterial complications of postpartum uterine involution in cattle. Anim Reprod Sci, 96:265-281.

Gabler C, Drillich M, Fischer C, Holder C, Heuwieser W, Einspanier R. 2009. Endometrial expression of selected transcripts involved in prostaglandin synthesis in cows with endometritis. Theriogenology, 71:993-1004.

Gabler C, Fischer C, Drillich M, Einspanier R, Heuwieser W. 2010. Time-dependent mRNA expression of selected pro-inflammatory factors in the endometrium of primiparous cows postpartum. Reprod Biol Endocrinol, 8:152. doi: 10.1186/1477-7827-8-152.

Galvão KN, Santos NR, Galvão JS, Gilbert RO. 2011. Association between endometritis and endometrial cytokine expression in postpartum Holstein cows. Theriogenology, 76:290-299.

Gärtner MA, Peter S, Jung M, Drillich M, Einspanier R, Gabler C. 2016. Increased mRNA expression of selected pro-inflammatory factors in inflamed bovine endometrium in vivo as well as in endometrial epithelial cells exposed to Bacillus pumilus in vitro. Reprod Fertil Dev, 28:982-294.

Giuliodori MJ, Magnasco RP, Becu-Villalobos D, Lacau-Mengido IM, Risco CA, de la Sota RL. 2013.
Clinical endometritis in an Argentinean herd of dairy cows: risk factors and reproductive efficiency. J Dairy Sci, 96:210-218.

Goldstone RJ, Talbot R, Schuberth HJ, Sandra O, Sheldon IM, Smith DG. 2014. Draft genome sequence of Escherichia coli MS499, isolated from the infected uterus of a postpartum cow with metritis. Genome Announc, 2:e00217-214. doi: 10.1128/genomeA.0021714.

Hailemariam D, Ibrahim S, Hoelker M, Drillich M, Heuwieser W, Looft C, Cinar MU, Tholen E, Schellander K, Tesfaye D. 2014. MicroRNA-regulated molecular mechanism underlying bovine subclinical endometritis. Reprod Fertil Dev, 26:898-913.

Herath S, Lilly ST, Fischer DP, Williams EJ, Dobson H, Bryant CE, Sheldon IM. 2009. Bacterial lipopolysaccharide induces an endocrine switch from prostaglandin F2alpha to prostaglandin E2 in bovine endometrium. Endocrinology, 150:1912-1920.

Hill J, Gilbert R. 2008. Reduced quality of bovine embryos cultured in media conditioned by exposure to an inflamed endometrium. Aust Vet J, 86:312-316.

Hoelker M, Salilew-Wondim D, Drillich M, Christine GB, Ghanem N, Goetze L, Tesfaye D, Schellander K, Heuwieser W. 2012. Transcriptional response of the bovine endometrium and embryo to endometrial polymorphonuclear neutrophil infiltration as an indicator of subclinical inflammation of the uterine environment. Reprod Fertil Dev, 24:778-793.

Ibrahim M, Peter S, Gärtner MA, Michel G, Jung M, Einspanier R, Gabler C. 2016. Increased mRNA expression of selected antimicrobial peptides around ovulation and during inflammatory processes in the bovine endometrium postpartum. Theriogenology, 86:2040-2053.

Jeon SJ, Cunha F, Ma X, Martinez N, Vieira-Neto A, Daetz R, Bicalho RC, Lima S, Santos JE, Jeong KC, Galvão KN. 2016. Uterine microbiota and immune parameters associated with fever in dairy cows with metritis. PLoS One, 11:e0165740. doi: 10.1371/journal.pone.0165740.

Jeon SJ, Cunha F, Vieira-Neto A, Bicalho RC, Lima S, Bicalho ML, Galvão KN. 2017. Blood as a route of transmission of uterine pathogens from the gut to the uterus in cows. Microbiome, 5:109. doi. org/10.1186/s40168-017-0328-9.

Jeon SJ, Lima FS, Vieira-Neto A, Machado VS, Lima SF, Bicalho RC, Santos JEP, Galvão KN. 2018. Shift of uterine microbiota associated with antibiotic treatment and cure of metritis in dairy cows. Vet Microbiol, 214:132-139.

Johnson GA, Bazer FW, Jaeger LA, Ka H, Garlow JE, Pfarrer C, Spencer TE, Burghardt RC. 2001. Muc-1, integrin, and osteopontin expression during the implantation cascade in sheep. Biol Reprod, 65:820828.

Kasimanickam R, Duffield TF, Foster RA, Gartley CJ, Leslie KE, Walton JS, Johnson WH. 2004. Endometrial cytology and ultrasonography for the detection of subclinical endometritis in postpartum dairy cows. Theriogenology, 62:9-23.

Kasimanickam R, Kasimanickam V, Kastelic JP. 
2014. Mucin 1 and cytokines mRNA in endometrium of dairy cows with postpartum uterine disease or repeat breeding. Theriogenology, 81:952-958.

Karstrup CC, Klitgaard K, Jensen TK, Agerholm JS, Pedersen HG. 2017. Presence of bacteria in the endometrium and placentomes of pregnant cows. Theriogenology, 99:41-47.

LeBlanc SJ, Duffield TF, Leslie KE, Bateman KG, Keefe GP, Walton JS, Johnson WH. 2002. Defining and diagnosing postpartum clinical endometritis and its impact on reproductive performance in dairy cows. $J$ Dairy Sci, 85:2223-2236.

LeBlanc SJ. 2010. Monitoring metabolic health of dairy cattle in the transition period. J Reprod Dev, 56:S29-S35.

LeBlanc SJ, Osawa T, Dubuc J. 2011. Reproductive tract defense and disease in postpartum dairy cows. Theriogenology, 76:1610-1618.

LeBlanc SJ. 2012. Interactions of metabolism, inflammation, and reproductive tract health in the postpartum period in dairy cattle. Reprod Domest Anim, 47:18-30.

Leroy JLMR, Van Soom A, Opsomer G, Bols PEJ. 2008. The consequences of metabolic changes in highyielding dairy cows on oocyte and embryo quality. Animal, 2:1120-1127.

Madoz LV, Giuliodori MJ, Jaureguiberry M, Plöntzke J, Drillich M, de la Sota RL. 2013. The relationship between endometrial cytology during estrous cycle and cutoff points for the diagnosis of subclinical endometritis in grazing dairy cows. J Dairy Sci, 96:4333-4339.

Madoz LV, Giuliodori MJ, Migliorisi AL, Jaureguiberry M, de la Sota RL. 2014. Endometrial cytology, biopsy, and bacteriology for the diagnosis of subclinical endometritis in grazing dairy cows. J Dairy Sci, 97:195-201.

Moore SG, Ericsson AC, Poock SE, Melendez P, Lucy MC. 2017. Hot topic: 16S rRNA gene sequencing reveals the microbiome of the virgin and pregnant bovine uterus. J Dairy Sci, 100:4953-4960.

Peter S, Michel G, Hahn A, Ibrahim M, LubkeBecker A, Jung M, Einspanier R, Gabler C. 2015. Puerperal influence of bovine uterine health status on the mRNA expression of pro-inflammatory factors. $J$ Physiol Pharmacol, 66:449-462.

Potter TJ, Guitian J, Fishwick J, Gordon PJ, Sheldon IM. 2010. Risk factors for clinical endometritis in postpartum dairy cattle. Theriogenology, 74:127-134.

Prunner I, Pothmann H, Wagener K, Giuliodori M, Huber J, Ehling-Schulz M, Drillich M. 2014. Dynamics of bacteriologic and cytologic changes in the uterus of postpartum dairy cows. Theriogenology, 82:1316-1322.

Saito S, Tsuda H, Michimata T. 2002. Prostaglandin D2 and reproduction. Am J Reprod Immunol, 47:295302.

Santos TMA, Gilbert R, Bicalho RC. 2011. Metagenomic analysis of the uterine bacterial microbiota in healthy and metritic postpartum dairy cows. J Dairy Sci, 94:291-302.
Santos TMA, Bicalho RC. 2012. Diversity and succession of bacterial communities in the uterine fluid of postpartum metritic, endometritic and healthy dairy cows. PLoS One, 7:e53048. doi: 10.1371/journal.pone.0053048.

Sheldon IM, Noakes DE, Rycroft AN, Pfeiffer DU, Dobson H. 2002. Influence of uterine bacterial contamination after parturition on ovarian dominant follicle selection and follicle growth and function in cattle. Reproduction, 123:837-845.

Sheldon IM, Lewis GS, LeBlanc S, Gilbert RO. 2006. Defining postpartum uterine disease in cattle. Theriogenology, 65:1516-1530.

Sheldon IM, Cronin J, Goetze L, Donofrio G, Schuberth H-J. 2009. Defining postpartum uterine disease and the mechanisms of infection and immunity in the female reproductive tract in cattle. Biol Reprod, 81:1025-1032.

Sheldon IM, Rycroft AN, Dogan B, Craven M, Bromfield JJ, Chandler A, Roberts MH, Price SB, Gilbert RO, Simpson KW. 2010. Specific strains of Escherichia coli are pathogenic for the endometrium of cattle and cause pelvic inflammatory disease in cattle and mice. PLoS One, 5: e9192. doi: 10.1371/journal.pone.0009192.

Sheldon IM, Cronin JG, Healey GD, Gabler C, Heuwieser W, Streyl D, Bromfield JJ, Miyamoto A, Fergani C, Dobson H. 2014. Innate immunity and inflammation of the bovine female reproductive tract in health and disease. Reproduction, 148:R41-R51.

Sheldon IM. 2015. Genes and environmental factors that influence disease resistance to microbes in the female reproductive tract of dairy cattle. Reprod Fertil Dev, 27:72-81.

Valour D, Hue I, Degrelle SA, Déjean S, Marot G, Dubois O, Germain G, Humblot P, Ponter A, Charpigny G, Grimard B. 2013. Pre- and post-partum mild underfeeding influences gene expression in the reproductive tract of cyclic dairy cows. Reprod Domest Anim, 48:484-499.

Wagener K, Drillich M, Baumgardt S, Kämpfer P, Busse HJ, Ehling-Schulz M. 2014a. Falsiporphyromonas endometrii gen. nov., sp. nov., isolated from the post-partum bovine uterus, and emended description of the genus Porphyromonas Shah and Collins 1988. Int J Syst Evol Microbiol, 64(Pt 2):642-649.

Wagener K, Grunert T, Prunner I, Ehling-Schulz M, Drillich M. 2014b. Dynamics of uterine infections with Escherichia coli, Streptococcus uberis and Trueperella pyogenes in post-partum dairy cows and their association with clinical endometritis. Vet $J, 202: 527-$ 532.

Wagener K, Prunner I, Pothmann H, Drillich M, Ehling-Schulz M. 2015. Diversity and health status specific fluctuations of intrauterine microbial communities in postpartum dairy cows. Vet Microbiol, 175:286-293.

Wagener K, Gabler C, Drillich M. 2017a. A review of the ongoing discussion about definition, diagnosis and pathomechanism of subclinical endometritis in dairy cows. Theriogenology, 94:21-30. 
Wagener K, Pothmann H, Prunner I, Peter S, Erber R, Aurich C, Drillich M, Gabler C. $2017 \mathrm{~b}$. Endometrial mRNA expression of selected proinflammatory factors and mucins in repeat breeder cows with and without subclinical endometritis. Theriogenology, 90:237-244.

Werner A, Suthar V, Plöntzke J, Heuwieser W. 2012. Relationship between bacteriological findings in the second and fourth weeks postpartum and uterine infection in dairy cows considering bacteriological results. J Dairy Sci, 95:7105-7114.

Westermann S, Drillich M, Kaufmann TB, Madoz
LV, Heuwieser W. 2010. A clinical approach to determine false positive findings of clinical endometritis by vaginoscopy by the use of uterine bacteriology and cytology in dairy cows. Theriogenology, 74:1248-1255. Williams EJ, Herath S, England GCW, Dobson H, Bryant CE, Sheldon IM. 2008. Effect of Escherichia coli infection of the bovine uterus from the whole animal to the cell. Animal, 2:1153-1157.

Zerbe H, Schuberth HJ, Engelke F, Frank J, Klug E, Leibold W. 2003. Development and comparison of in vivo and in vitro models for endometritis in cows and mares. Theriogenology, 60:209-223. 